\title{
The Dynamic Nature of Interlanguage Sentential Negation of Indonesian EFL Learners
}

\author{
Fauziati, Endang*, Tri Santoso, Nur Hidayat, Indah Safitri Mahargiani \\ Faculty of Teacher Training and Education, Universitas Muhammadiyah Surakarta, Indonesia
}

Received June 23, 2020; Revised August 25, 2020; Accepted September 11, 2020

\section{Cite This Paper in the following Citation Styles}

(a): [1] Fauziati, Endang, Tri Santoso, Nur Hidayat, Indah Safitri Mahargiani , "The Dynamic Nature of Interlanguage Sentential Negation of Indonesian EFL Learners," Universal Journal of Educational Research, Vol. 8, No. 11, pp. 5203-5211, 2020. DOI: 10.13189/ujer.2020.081121.

(b): Fauziati, Endang, Tri Santoso, Nur Hidayat, Indah Safitri Mahargiani (2020). The Dynamic Nature of Interlanguage Sentential Negation of Indonesian EFL Learners. Universal Journal of Educational Research, 8(11), 5203-5211. DOI: 10.13189/ujer.2020.081121.

Copyright $\odot 2020$ by authors, all rights reserved. Authors agree that this article remains permanently open access under the terms of the Creative Commons Attribution License 4.0 International License

\begin{abstract}
This cross sectional study attempted to provide empirical study on interlanguage sentential negation of Indonesian EFL learners, particularly the dynamic nature viewed from the stages of development and the number of grammatical error types in each stage. The subjects were Indonesian EFL learners, consisting of four groups from different grades. The data were collected through translation test and analyzed using Lightbown \& Spada's framework and error analysis framework. The result indicated that the development stages were not in line with Lightbown \& Spada, instead they were represented in three stages of development. Its dynamicity was also depicted by the reduction of grammatical error types at each level. The conclusion was that the learners' interlanguage sentential negation was dynamic, developing closer and closer to the target language through three stages. It is suggested that educators not to give pressure to the learners to get things right at the first place. In addition, their instruction should match the learners' stage of development.
\end{abstract}

Keywords Dynamic Nature of Interlanguage, Sentential Negation, EFL Learner

\section{Introduction}

Interlanguage, the interim grammar formed by learners while learning a second language, is believed to be a halfway house between native language (NL) and target language (TL). Saville-Troike (2012) called it 'transfer', in a sense that it is a transition of prior knowledge from NL to TL, as one of the processes involved in IL development. It is believed that learner errors represent cognitive mechanism used by the learners to determine the TL structure. And in the process they create an IL of developmental sequences which often include grammatically incorrect structures. This shows the learner's true level of understanding of the structures the TL (Lightbown \& Spada, 2006). As they receive more linguistic input, they reexamine the structure and revise their idea of the rules and patterns.

This study focuses on the EFL interlanguage sentential negation, also known as a negative construction. It is worth studying since it is one of the basic syntactic structures that should be mastered by EFL learners, including Indonesian EFL learners. As observable phenomena indicate that the Indonesian EFL learners' negation construction develops gradually over time during the learning course, as examples from the data collected from different levels state "My father not washing his car", "My father not wash his car"; "My father don't wash his car", and "My father did not wash his car". This phenomenon becomes the focus of the current study.

Studies on the development of English negation by EFL learners from different perspectives can be briefly detected back to the 1970s and 1980s. Klima \& Bellugi (1966), Butterworth (1972) and Wode (1978) conducted early studies on negation in the field of SLA and concentrated 
their studies on the development of English negation by learners of English as their first language. Meanwhile, Cancino, Rosansky \& Schumann (1978) and Felix (1981) studied the same negation development by second language learners.

Klima \& Bellugi had identified three stages in the development of English negation as follows: stage one: place the negator (e.g., no, not) whether before or after the rest of the utterance; stage two: the negator is placed inside the utterance between the subject and verb (the auxiliary such as, is, are, and do are still absent; and stage three: some auxiliaries are present (the negator is correctly placed to the right of the auxiliary). Meanwhile, Wode (1977) who used data from different languages, mainly English, German, and Swedish proposed five stages for the development of negation systems in natural languages. These are: stage one: anaphoric negation; stage two: non-anaphoric external negation; stage three: internal "be" negation; stage four: internal full verb negation, and "don't" imperative; and stage five: suppletive non-imperative "do". It has been confirmed then that children learning English as a first language go through some stages before producing target-like negative construction.

Most of the research done on the development of English negation by L2 learners focused on the identification of stages of development by contrasting the data with those of Klima and Bellugi (1966). Cancino, Rosansky and Schumann (1978) studied the interlanguage of six native speakers of Spanish learning English in a natural setting found a developmental pattern as follows: (1) stage one: no $\mathrm{V}$, the learners placed the negative marker (no) before verbs as in the constructions "I no use television"; (2) stage two: don't V, the auxiliary do began to appear, although not appropriately inflected for tense or number, as in he don't like it; (3) stage three: auxiliary-negation, sentences with modal auxiliaries and the copula followed by the negator as in "somebody is not coming in"; (4) and stage four: analyzed don't, disappearance of no V, learners correctly inflected auxiliary do to form negative sentences.

Stauble (1984) studied the acquisition of English negation by speakers of Spanish and Japanese noticed three stages of development as follows: (1) stage one was characterized by sentences in which no and don't appeared before verbs. Negator no $(t)$ might also appear together with other lexical categories; (2) stage two, the learners could appropriately inflect auxiliary do while uncontracted negator did not appear after auxiliaries and the copula; and (3) the learners could mark agreement and tense on auxiliary do (do-does/did) and place negative markers after auxiliaries and the copula. Such a pattern of negation acquisition was common for both the Spanish and the Japanese speakers.

Lightbown \& Spada (2006) proposed four stages in the developmental sequence of negation. Stage one: the negator (no or not) is placed before the verb or thing negated as in No cake. No have money. I not understand. Stage two: the negator don't is used but it is not marked for person, number, or tense and it is often used before modal auxiliaries, as in She don't like me. I don't can drive. Stage three: the negator is placed after BE and modal auxiliary. However, the negator don't is used and it continues to be unmarked for person, number or tense, as in You cannot see it. She was not happy. He don't understand. Stage four: the negator don't is marked for person, number and tense, as in She doesn't understand. We didn't go to the zoo.

Recent studies on negation development by EFL learners had been conducted, among others, by Susana et al. (2009); Eisouh (2011); Khany \& Bazyar (2013); Yazdfazelia \& Maleckzadehb (2014); and Fuli \& Shuang (2014). Most of the studies agree that like first language learners of English, EFL learners passed through sequences of development. What was learned early by first language learners was also learned early by EFL learners. They followed a path that was similar to the stages for first language acquisition. However, EFL learners from different first language backgrounds behaved somewhat differently within these stages. Meanwhile, Eisouh (2011) who studied Jordan EFL learners found that the development followed the similar syntactic parameters of stages two and three proposed by Klima and Bellugi though it did not follow a linear development nor achieve high accuracy. Yazdfazelia \& Maleckzadeh's (2014) studied Persian EFL learners showed that using negation was different in different levels and across both comprehension and production.

In sum, most recent studies on negation development by EFL learners agree on defining the stages of development in the acquisition of negation. The development more or less corresponds to that of the native speakers of English. These studies also reported the existence of cases of unanalyzed do, the constructions in which the auxiliary failed to agree with the subject of the clause, and the failure to achieve high accuracy.

Most of the previous studies reviewed have been dedicated to the development of English negation of EFL learners with Jordan, Persian, Spanish, Japanese, and Chinese language background. There were just very few studies used EFL learners with Indonesian background as research subjects. This is one of the reasons why the current study was worth conducting. So far, there has not been any research carried out on negation development by relating its explanation to interlanguage theories. This is another reason why the current study was carried out.

The interlanguage theory believes that learner language is dynamic in nature (Saville-Troike, 2012). Its language system is continuously changing, as new knowledge of the L2 is put in, an adaptation in the language competence already acquired takes place. The current study would like to address the dynamic nature of Indonesian EFL learners' sentential negation using the perspectives of error analysis, interlanguage analysis, as well as developmental studies. It 
is expected that this study gives a contribution to SLA research on Indonesian EFL learners, particularly dealing with the acquisition of sentential negation and EFL teaching.

This study tries to provide insight into the dynamicity of the learners' interlanguage negation which was represented through two ways. The first way was through comparison model, that is, the learners' negative construction was contrasted with L2 stages of negation development discussed by Lightbown and Spada (2006). In this manner, its dynamic nature was seen through the changes or the development of their negation construction. The second way was through the error analysis framework, that is, the learners' negative construction was analyzed to find out the types of grammatical error they committed. In this mode, its dynamicity was seen through the number of grammatical error types they produced at different levels.

To reach the intended goal, the following research questions were raised: (1) what sentential negative construction did the EFL learners of low and high beginning levels and low and high intermediate levels produce?; (2) how was the dynamicity of their sentential negative construction viewed from the stage of development model proposed by Lightbrown \& Spada?; (3) what types of grammatical error did they produce?; (4) how was the dynamicity of their interlanguage negative construction viewed from the stages of development and the number of error types produced?

\section{Methodology}

This study was a qualitative research of SLA in a classroom context with a cross-sectional approach (Ellis, 2006). Cross-sectional approach was chosen because it can capture information based on data collected for a specific point in time. The subjects were 40 students consisting of 4 different groups (grades) with different levels of English proficiency, namely: the $7^{\text {th }} \& 9^{\text {th }}$ grade of Junior High School as representatives of foundations or low beginning and fundamental skills or high beginning levels of EFL learners and the $11^{\text {th }} \& 12^{\text {th }}$ grade of Senior High School students of Semarang regency as representatives of intermediate skills or low intermediate and intermediate levels of EFL learners.

The data elicitation was conducted through translation test that was designed by the researcher. The test was checked for the validity and reliability in pilot tests. The test consisted of 30 Indonesian negative sentences which comprise 10 nominal sentences, 10 verbal sentences, and 10 sentences with modal auxiliary.

All the subjects were given the translation test paper and were required to translate the Indonesian sentences into English. The translation of the sentences was the result of their first thought. The whole activity was under the supervision of the researchers. The translation test aimed to collect information about the students' responses to various negative sentences. And the result of the translation was used as data of this study.

The data were analyzed using comparison model and error analysis framework. Within comparison model, the data were classified based on the types of the structure the students produced in order to find out the dominant type, that is, the negative constructions used by the majority of the students at each level. Each group represented a different stage of development. The dominant types of negative constructions from the four groups were then contrasted with the developmental sequence of negation for L2 learners proposed by Lightbown \& Spada (2006) to find out the dynamic changes or the development of the learners' negative construction. Within error analysis mode, the data were first identified using James's (2013) error analysis framework in order to find out the grammatical errors produced by the learners at each level. The data were classified based on linguistic and surface strategy taxonomy combined to find out the error types produced at each level. The dynamicity was represented by the reduction of the error types produced by the learners from one level to the next. Finally, interpretation of the data was done based on the relevant theory.

\section{Results}

Four aspects discussed in this section are as follows: (1) the sentential negative constructions produced by the learners of low and high beginning levels and low and high intermediate levels, (2) the stage of development of the sentential negative construction, (3) the grammatical error types produced by the learners of low and high beginning levels and low and high intermediate levels, and (4) the dynamicity of the learners' interlanguage negative construction viewed from the number of error types produced?

\section{The Sentential Negative Construction Produced by the Learners of Four Different Levels}

1. Sentential Negation Construction Produced by the Low Beginning Level: Result of analysis indicates that the $85 \%$ of the students' common construction produced was not/no + noun/adjective for nominal sentence. This was produced by $85 \%$ of the students. According to Lightbrown \& Spada (2006) they were at stage one level of negation development in which the predominant negation construction was the use of no or not before nouns and adjective. For examples, the learners wrote "They not killer", Cigarette no good for health", Students not in the classroom". Similarly, their verbal negative sentence was also characterized by the use of not/no + verb as in "Fino not swim last week", "Andira not believe with the news", and Mother not make new cloth for me". This type of 
negation construction was produced by $85 \%$ of the students and this was categorized as stage one level of development. Correspondingly, the students' construction of negation with modal auxiliary was typified by the use of not/no + modal + verb as in "We not can sleep last night", "I not must come on time", "I no can come to birthday party". This was the typical negation construction produced by $80 \%$ of the students under this study and this was classified as stage one level of development according to Lightbrown \& Spada (2006).

2. Sentential Negation Construction Produced by the High Beginning Level: The sentential negation construction produced by the EFL learners of the high beginning was more accurate than those of the low beginning level. More learners appeared to have been able to use no, not, and don't didn't a bit more properly (20\%). However, the majority of the learners (80\%) still used unanalyzed $B E+$ not + noun/adjective in their negative construction for nominal sentence. The use of $\mathrm{BE}$, however, was remained unanalyzed such as in "Mr. Chandra is not at home yesterday”, "There is not students in class", and "The woman is not satisfied with his clothes". They used BE (is, am, are, was, were) inaccurately. It can be said that they could produce negative sentence. The same condition occurred to the negation construction of verbal sentence. Around $80 \%$ of the students used unanalyzed don't + verb in their verbal negative sentence, such as "My father do not wash his car”, "Mother did not make new cloth to me”, and "Andini does not brushing teeth last night. Surprisingly however, the majority of the students (80\%) could produce more proper negation with modal auxiliary, that is, analyzed modal + not + verb such as "I must not come on time”, "They will not go to Bali”, and "You may not bring Hand phone”. Around $20 \%$ of the students used unanalyzed modal auxiliary can and must. They used these for both present as well as past events. According to Lightbrown \& Spada's framework (2006), these learners reached stage two of negation development.

3. Sentential Negation Construction Produced by Low Intermediate Level: The third group was at the low intermediate level. The data indicate that more learners at this level could produce negation construction better than those of the previous levels. However, some of the constructions reflected an interlanguage system. To produce negation of nominal sentence, around $60 \%$ of the learners' unanalyzed $B E+$ not + noun/adjective. They conflated the use of the present tense $\mathrm{BE}$ (is, am, are) and the past tense BE (was, were) as in "The house was not wide and big”, "The woman is not satisfied with her new cloth" and "Mr. Chandra is not at home yesterday but he is in Bandung”. According to Lightbrown \& Spada (2006) the majority of the learners were still at stage two of negation development. The rest of the students were able to produce correct negation construction of the nominal sentence. This was in line with their negation construction of verbal sentence. The majority of the learners (60\%) used unanalyzed don't + verb, such as "My father do not wash his car', "Mother does not make new clothes for me", "Andini does nor brushing your teeth lastnight". The students conflated the use of helping verb do/does/did as they failed to distinguish the use of these helping verbs. However, the learners' negation construction with modal auxiliary was well developed in a sense that the majority of the learners (70\%) could construct negation with modal auxiliary sentence "unanalyzed modal + not + verb". On close examination, however, mostly the students failed to use past modal auxiliary for the past event such as "We can not sleep last night", "I can not come to the birthday party", and We can not go anywhere. This was classified as stage two of negation development.

4. Sentential Negation Construction Produced by High Intermediate Level: The data indicate that the high intermediate level learners could produce much better negative construction than the previous ones. They appeared to have acquired a significant amount of knowledge on negation. Based on Lightbrown \& Spada's (2006) development stage, their acquisition of negation reached stage three of the development. The majority of the students (75\%) produced analyzed $B E+$ not + noun/adjective for negation with nominal sentence such as "Smoking is not good for health”, “They are not killers”, and "Mr. Chandra was not at home yesterday". Apparently that their negation construction with verbal sentence was well developed as well. The majority of the students (80\%) produced analyzed don't + verb as in "The football player does not play well”, "Fino didn't swim last week”, and "Nino does not like reading novel". And the rest of the students (20\%) still produced unanalyzed don't + verb but none of them produced no/not + verb. According to Lightbrown \& Spada's (2006), the majority of the students apparently reached stage four of negation development. This corresponds to their negation construction with auxiliary verb as in general the students (80\%) could produce analyzed modal auxiliary + not + verb such as "Sandro must not wear his shoes", "The students may not eat in class", and "You may not bring mobile phone in class”.

\section{The Stage of Development of the Students' Sentential Negative Construction}

The data described above indicate how the majority of students constructed negation with nominal sentence, verbal sentence, and sentence with modal. Each type of construction represents the learner's version of the negative construction they learned at a particular level and the construction changes all the time as the learners had the opportunity to improve their language knowledge. Table below shows the negative construction produced by the majority of the learners in four different levels. 
Table 1. Negative Construction Produced by the Majority of the Learners

\begin{tabular}{|c|c|c|}
\hline No & level & Negation construction \\
\hline 1. & $\begin{array}{c}\text { Low } \\
\text { beginning }\end{array}$ & $\begin{array}{l}\text { Nominal sentence: } \text { not/no + noun/adjective } \\
\text { Verbal sentence: } n o t / n o+v e r b \\
\text { Sentence with Modals: not/no + modal + verb }\end{array}$ \\
\hline 2. & $\begin{array}{c}\text { High } \\
\text { beginning }\end{array}$ & $\begin{array}{l}\text { Nominal sentence: unanalyzed } B E+\text { not }+ \\
\text { noun/adjective } \\
\text { Verbal sentence: unanalyzed don't }+ \text { verb } \\
\text { Sentence with Modals: : unanalyzed modal }+ \text { not } \\
+ \text { verb }\end{array}$ \\
\hline 3. & $\begin{array}{c}\text { Low } \\
\text { intermediate }\end{array}$ & $\begin{array}{l}\text { Nominal sentence: unanalyzed BE }+ \text { not }+ \\
\text { noun/adjective } \\
\text { Verbal sentence: unanalyzed don't }+ \text { verb } \\
\text { Sentence with Modals: : unanalyzed modal +not } \\
+ \text { verb }\end{array}$ \\
\hline 4. & $\begin{array}{c}\text { High } \\
\text { intermediate }\end{array}$ & $\begin{array}{l}\text { Nominal sentence: analyzed } B E+\text { not }+ \\
\text { noun/adjective } \\
\text { Verbal sentence: analyzed don't }+ \text { verb } \\
\text { Sentence with Modals: analyzed modal }+ \text { not }+ \\
\text { verb }\end{array}$ \\
\hline
\end{tabular}

The data showed that the majority of the learners went through the three stages of negation development based on Lightbrown \& Spada (2006). They are stage one (not/no + noun/adjective for nominal sentence, not/no + verb for verbal sentence, not/no + modal + verb for sentence with modal auxiliary); stage two (unanalyzed $B E+$ not + noun/adjective for nominal sentence, unanalyzed don't + verb for verbal sentence, modal + not + verb for sentence with modal auxiliary); and stage three (analyzed $B E+$ not + noun/adjective for nominal sentence, analyzed don't + verb for verbal sentence, modal + not + verb for sentence with modal auxiliary. The stages of the development can be summarized in the table 2 below.

\section{Grammatical Error Types Produced by the Learners at Four Different Levels}

The result of error analysis indicates that there were various types of grammatical errors produced by the learners at all levels. However, the number of error types was reduced from one level to the next. The students from low beginning levels produced the highest number of grammatical error type and the least number by the students from the high intermediate level. There were fourteen (14) different types of grammatical error produced by the students of low beginning level as shown in table 3; eight (8) types of grammatical errors produced by the high beginning level as shown in table 4, four types (4) of grammatical errors committed by the low intermediated level as shown in table 5, and four (4) types grammatical error made by the high intermediate level as shown in Table 6.

Table 2. The Stages of the Learners' Negation Development

\begin{tabular}{cccc}
\hline Low beginning Level & High Beginning Level & Low Intermediate Level & High Intermediate Level \\
\hline $\begin{array}{c}\text { Stage I: Negator (no/not) is placed } \\
\text { before noun/adjective/verb/ } \\
\text { modal auxiliary }\end{array}$ & $\begin{array}{c}\text { Stage II: Negator not after } \\
\text { unanalyzed BE; un analyzed } \\
\text { don't before verb; not after } \\
\text { unanalyzed modal for tense }\end{array}$ & $\begin{array}{c}\text { Stage II: Negator not after } \\
\text { unanalyzed BE; un analyzed } \\
\text { don't/ before verb; not after } \\
\text { unanalyzed modal for tense }\end{array}$ & $\begin{array}{c}\text { Stage III: Negator not after } \\
\text { analyzed BE; analyzed don't } \\
\text { before verb; not after analyzed } \\
\text { modal for tense }\end{array}$ \\
$\begin{array}{c}\text { Mr. Chandra is not at home } \\
\text { yesterday; }\end{array}$ & $\begin{array}{c}\text { Mr. Chandra is not at home } \\
\text { yesterday }\end{array}$ & $\begin{array}{c}\text { Mr. Chandra was not at home } \\
\text { yesterday }\end{array}$ \\
The guests not come on this & $\begin{array}{c}\text { The guests do not come this } \\
\text { morning }\end{array}$ & $\begin{array}{c}\text { The guest does not come this } \\
\text { morning }\end{array}$ & $\begin{array}{c}\text { The guest did not come this } \\
\text { morning }\end{array}$ \\
We not can sleep last night & We cannot sleep last night & We cannot sleep last night & We could not sleep last night \\
\hline
\end{tabular}

Table 3. Grammatical Error Types Produced by the Learners at Low Beginning Level

\begin{tabular}{|c|c|c|}
\hline NO & Error Type & Example \\
\hline 1. & The Use of Helping BE instead of Verb do/does/did & $\begin{array}{l}\text { Andira isn't believe with that news } \\
\text { Andini isn't brush teeth lastnight }\end{array}$ \\
\hline 2. & $\begin{array}{c}\text { Omission of Helping Verb do/does/did while Selecting } \\
\text { Verb-ing instead of Verb Infinitive }\end{array}$ & $\begin{array}{l}\text { My father not washing his car } \\
\text { Football player not playing with good }\end{array}$ \\
\hline 3. & The Omission of Helping Verb do/does/did & Mother not make new cloth to me \\
\hline 4. & Omission of Bound Morpheme $\{-\mathrm{S}\}$ as Plural Marker & They aren't killer \\
\hline 5. & Omission of BE as full Verb & Mr. chandra not in house yesterday but he is in bandung \\
\hline 6. & Wrong Selection of BE for the past Tense & Mr. Chandra isn't on his house yesterday but he is in Bandung \\
\hline 7. & Wrong Selection of Helping Verb do/does & Nino don't like reading a novel \\
\hline 8. & Addition of determiner & $\begin{array}{l}\text { We don't have a money for buy a TV } \\
\text { Mother isn't make a new cloth for me }\end{array}$ \\
\hline 9. & Wrong selection of Preposition & Andira is not believe with the news \\
\hline 10. & Omission of Possessive pronoun & My father not wash the car \\
\hline 11. & $\begin{array}{c}\text { Wrong Selection of Verb form for the Present Continuous } \\
\text { Tense }\end{array}$ & I am not talk with teacher now \\
\hline 12. & Wrong Selection of Auxiliary for the past Tense Form & We can’t sleep lastnight \\
\hline 13. & $\begin{array}{c}\text { Omission of Helping Verb do/does while Using Negator No } \\
\text { instead of not }\end{array}$ & $\begin{array}{l}\text { My father no wash the car } \\
\text { Andira no belief with the news }\end{array}$ \\
\hline 14. & Misplacement of not and the Choice of No instead of not & I no must come right time \\
\hline
\end{tabular}


Table 4. Grammatical Error Types Produced by the Learners at High Beginning Level

\begin{tabular}{|c|c|c|}
\hline NO & Error Type & Example \\
\hline 1. & The use of Helping Verb BE instead of do/does/did & Nino is not like reading a novel \\
\hline 2. & $\begin{array}{c}\text { Omission of do/does/did while selecting Verb-ing instead of Verb } \\
\text { Infinitive }\end{array}$ & Andini not brushing teeth lastnight \\
\hline 3. & Omission of helping verb do/does/did & $\begin{array}{l}\text { My father not wash her car } \\
\text { Andira not believe the news }\end{array}$ \\
\hline 4. & Omission of Bound Morpheme $\{-\mathrm{S}\}$ as Plural Marker & $\begin{array}{l}\text { They not killer } \\
\text { They are not killer }\end{array}$ \\
\hline 5. & Omission of BE as a Full Verb & Mr. Chandra not at home yesterday but he was in Bandung \\
\hline 6. & Wrong Selection of BE for past Event & $\begin{array}{c}\text { Mr. Chandra is not at home yesterday but he was in } \\
\text { Bandung }\end{array}$ \\
\hline 7. & Wrong selection of Preposition & Andira does not believe with that news \\
\hline 8. & Wrong selection of possessive pronoun & The woman was not satisfied with his new clothes \\
\hline
\end{tabular}

Table 5. Grammatical Error Types Produced by the Learners at Low Intermediate Level

\begin{tabular}{|c|c|c|}
\hline NO & Error Type & Example \\
\hline 1. & $\begin{array}{c}\text { Omission of do/does/did while selecting Verb-ing instead of Verb } \\
\text { Infinitive }\end{array}$ & Andini not brushing teeth lastnight \\
\hline 2. & Omission of helping verb do/does/did & $\begin{array}{l}\text { My father not wash her car } \\
\text { Andira not believe the news }\end{array}$ \\
\hline 3. & Omission of Bound Morpheme $\{-\mathrm{S}\}$ as Plural Marker & $\begin{array}{l}\text { They not killer } \\
\text { They are not killer }\end{array}$ \\
\hline 4. & Omission of BE as a Full Verb & Mr. Chandra not at home yesterday but he was in Bandung \\
\hline
\end{tabular}

Table 6. Grammatical Error Types Produced by the Learners at High Intermediate Level

\begin{tabular}{|c|c|c|}
\hline NO & Error Type & Example \\
\hline 1. & $\begin{array}{c}\text { Omission of do/does/did while selecting Verb-ing instead of Verb } \\
\text { Infinitive }\end{array}$ & Andini not brushing teeth lastnight \\
\hline 2. & Omission of helping verb do/does/did & $\begin{array}{l}\text { My father not wash her car } \\
\text { Andira not believe the news }\end{array}$ \\
\hline 3. & Omission of Bound Morpheme $\{-\mathrm{S}\}$ as Plural Marker & $\begin{array}{l}\text { They not killer } \\
\text { They are not killer }\end{array}$ \\
\hline 4. & Omission of BE as a Full Verb & Mr. Chandra not at home yesterday but he was in Bandung \\
\hline
\end{tabular}

\section{Dynamic Nature of Learners' Interlanguage Negative Construction Viewed from the Number of Error Types Produced}

The result of error analysis indicates that the learners produced fewer types of grammatical errors on their translation work, from 14 types at low elementary level to 4 types at intermediate level. This means that learning process could develop their target language knowledge. Some error types produced by elementary level of learners no longer appeared in the works of intermediate level of learners. The learners' interlanguage negative construction was dynamic since grammar was learnable. The unlearned grammars (the use of helping verb be instead of do/does/did, wrong selection of be for the past tense, wrong selection of helping verb do/does, addition of determiner, wrong selection of preposition, omission of possessive pronoun, wrong selection of verb form for the present continuous tense, wrong selection of auxiliary for the past tense form, omission of helping verb do/does while using negator no instead of not, and misplacement of not and the choice of no instead of not) at low beginning level were finally learned at intermediate level.

Learning process had the potential to prevent the learners from producing particular grammatical items mentioned above. It seemed that learning process provided the learners with the needed information about particular grammatical rules; the learners then could incorporate the learned items into their developing system. By so doing, they continually acquired more and more grammatical knowledge of negation. Consequently they produced fewer types of grammatical error, as shown in the tables below. 
Table 7. Reduction of the Number of Grammatical Error Types

\begin{tabular}{|c|c|c|c|c|}
\hline NO & Low Beginning Level & $\begin{array}{c}\text { High } \\
\text { Beginning } \\
\text { Level } \\
\end{array}$ & $\begin{array}{c}\text { Low } \\
\text { Intermediate } \\
\text { Level } \\
\end{array}$ & $\begin{array}{l}\text { Intermedia } \\
\text { te level }\end{array}$ \\
\hline 1. & The Use of Helping BE instead of Verb do/does/did & $\sqrt{ }$ & & \\
\hline 2. & $\begin{array}{l}\text { Omission of Helping Verb do/does/did while Selecting Verb-ing instead } \\
\text { of Verb Infinitive }\end{array}$ & $\sqrt{ }$ & $\sqrt{ }$ & $\sqrt{ }$ \\
\hline 3. & The Omission of Helping Verb do/does/did & $\sqrt{ }$ & $\sqrt{ }$ & $\sqrt{ }$ \\
\hline 4. & Omission of Bound Morpheme $\{-\mathrm{S}\}$ as Plural Marker & $\sqrt{ }$ & $\sqrt{ }$ & $\sqrt{ }$ \\
\hline 5. & Omission of BE as full Verb & $\sqrt{ }$ & $\sqrt{ }$ & $\sqrt{ }$ \\
\hline 6. & Wrong Selection of BE for the past Tense & $\sqrt{ }$ & & \\
\hline 7. & Wrong Selection of Helping Verb do/does & $\sqrt{ }$ & - & - \\
\hline 8. & Addition of determiner & $\sqrt{ }$ & - & - \\
\hline 9. & Wrong selection of Preposition & - & - & - \\
\hline 10. & Omission of Possessive pronoun & - & - & - \\
\hline 11. & Wrong Selection of Verb form for the Present Continuous Tense & - & - & - \\
\hline 12. & Wrong Selection of Auxiliary for the past Tense Form & - & - & - \\
\hline 13. & Omission of Helping Verb do/does while Using Negator No instead of not & - & - & - \\
\hline 14. & Misplacement of not and the Choice of No instead of not & - & - & - \\
\hline
\end{tabular}

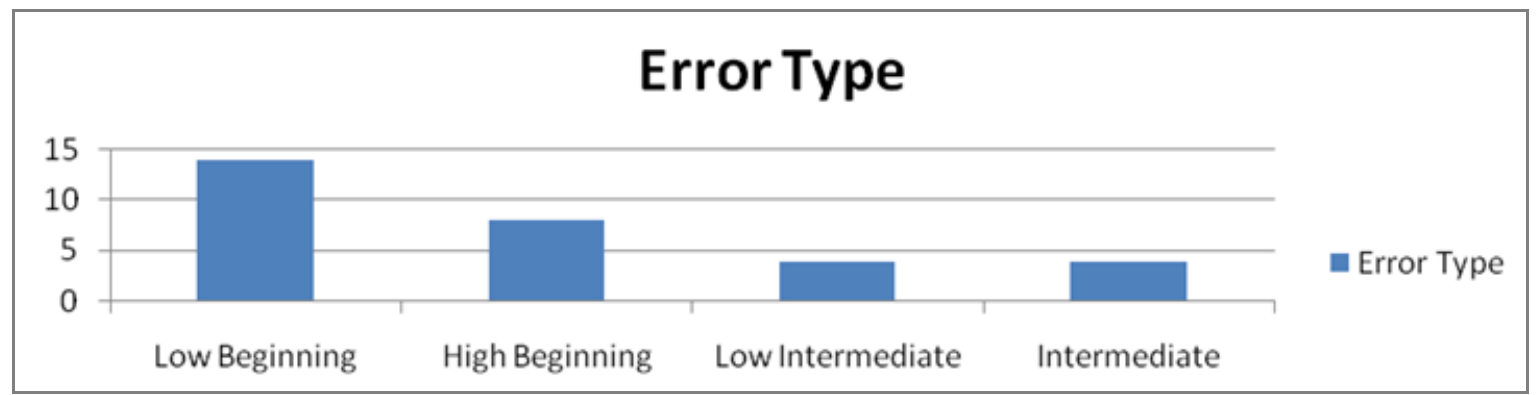

\section{Discussion}

\section{Dynamic Nature of Negative Construction Viewed from the Stage of Development}

The description above indicates that the majority of the students developed their knowledge of negative construction. Each type of construction represents the learners' version at a particular period of learning course and the construction changed all the time as the learners had the opportunity to improve their target language knowledge. The change of the construction represents a series of learning stages. This study found three stages of developmental sequence of English negation namely: (1) Negator (no/not) is placed before noun/adjective/verb/modal auxiliary, (2) Negator not after unanalyzed BE; un analyzed don't before verb; not after unanalyzed modal for tense, and (3) Negator not after analyzed BE; analyzed don't before verb; not after analyzed modal for tense.

The current finding does not correspond with the findings of Cancino, Rosansky, \& Schumann (1978), Stauble (1978), and Lightbrown \& Spada (2006) who maintained four stages in the developmental sequence of negation. However, this supports Susana et al. (2009), Eisouh (2011), Khany \& Bazyar (2013), Yazdfazelia \& Maleckzadehb (2014), and Liu Shuang (2014) who claimed that negative sentences by EFL learners follow a similar stage found in first language acquisition, however, behaving differently within the stages.

The current study found that the learners proceeded through three stages. It appeared that they prolonged the development of stage 2 that was represented by the learners at the high beginning and low intermediate level. This condition is very likely since Indonesian students acquire English non naturally, through classroom teaching learning process. At the beginning level they got grammar-based teaching, learning linguistic components which include teaching items such as present tense, past tense, and future tense. They, therefore, already learned these items but could not use them accurately. As they entered the next level their language knowledge developed and they could use these items more accurately than before.

The negative construction the learners produced changed as they moved from low beginning level to intermediate level. Samples of these negative constructions 
indicate that there was significant change from low beginning level to high beginning level and from low intermediate level to intermediate level. However, there was a significant plateau from high beginning level to low intermediate level. The disappearance of Negator (no/not) + noun/adjective/verb/modal auxiliary resulted in a variety of negative constructions they used over time. And the construction of Negator not after unanalyzed BE; un analyzed don't before verb; not after unanalyzed modal for tense were used for a longer period of learning course.

At stage one the learners' negative construction was much influenced by their native language (Indonesian); and this was the result of cognitive strategy that could be simply stated as "they used what they knew". The beginning learners had nothing to draw on but their native language to accomplish the task. For example, the negative sentence "Nino no like to read novel" is very similar to Indonesian negative construction "Nino tidak (no) suka (like) membaca (read) novel (novel)". The lower intermediate learners had acquired a certain amount of knowledge about English and used it to accomplish the task. However, they often did it imperfectly as represented at stage two "Nino do not like to read novel". The intermediate learners had acquired considerable knowledge of English and could use it more appropriately as represented at stage three "Nino does not like reading novel". This finding supports Perales, Mayo, and Liceras (2009) and Ahmad (2012) who found that the older learners perform better than the younger ones in language proficiency, including in the acquisition of sentential negation.

Not all the intermediate learners, however, reached stage three of negation development. Several of them reached a plateau in their development and remained at stage two in their negation development. This is in line with Yuhair's (2011) finding that EFL learners moved along a continuum of negation development but they did not achieve high accuracy. This condition is considered common in second language acquisition. There is a state during the process of second language acquisition, where the target language is not acquired completely yet as the learners are at the transition period which represents the state of their interlanguage development (Saville-Troike, 2012). In general, however, the development of negation from the beginning level to the intermediate level was significant. This means that their interlanguage sentential negation was developing. It was dynamic.

\section{Dynamic Nature of the Negative Construction Viewed from the Error Types Produced}

The result indicates that the learners produced fewer and fewer types of grammatical errors, from 14 error types at low elementary level to 4 error types at the intermediate level. This means that negation is learnable since English negation, like any other grammatical aspects, is usually taught at Indonesian schoolings from beginning level. Some grammatical aspects which were not yet learned at the beginning level were eventually learned at the next level of learning course.

The occurrence of error type indicates that the learners had not yet learned a particular grammatical aspect and its disappearance indicates that they learned it already. And the learning process contributes to this process. However, the learning process seems quite cognitively demanding. Negation was rather difficult to comprehend by the learners at the beginning level. One main factor which contributes to this difficulty is that there are some differences between English and Indonesia negation. While in English, the form of negation is known as no or not which can be applied to negate the subject, the predicate or the verb, and the object, in Indonesian negation is simply formed by adding negator word tidak or bukan to the word negated. Indonesian has no tense system and this posed difficulty for the EFL learners in learning negation. This view is well supported by Eisouh (2011) that EFL Students' imperfect mastery over tense may have accounted for most errors.

The reduction of error types indicates that actual process of learning occurred as the learners continually interacted with external forces such as pedagogical intervention from the teachers. Therefore, their knowledge about negation was never the same at any two points in time. As the learning process took place they would constantly test their hypotheses about negation and tried to revise them to be more in accordance with the target language. In this way their interlanguage sentential negation developed from a very primitive deviant version of the target language shown at stage one to progressively more target-like versions as shown at stage three. It was dynamic and was constantly changing. This view is in line with Saville-Troike (2012) that the process of constant revision and extension of rules is a feature of the inherent instability of interlanguage. The learners' development of negation, however, was non-linear in the sense that the learning did not occur smoothly. They did not jump from one stage to the next. This corresponds with Khany \& Bazyar (2014) who maintained that negation development occurs in an incremental manner and the resetting of target language properties is possible with the increasing level of proficiency.

\section{Conclusions and Implication}

The researchers could conclude that the EFL Indonesian learners' sentential negative construction was dynamic, developing through three stages. Its developmental stage was incompatible with the L2 negation development proposed by Lightbrown \& Spada in 2006 since the learners acquired negation non naturally in a classroom setting. Their knowledge of negation was dependent on the teachers' teaching the grammar material to them. Its 
dynamicity was also represented by the number grammatical error types which were reduced at each level as the result of learning process.

This empirical study provides evidence of EFL learners' strategies in learning negation, rather than as signs of their incompetence. They appeared to have been working creatively with the TL negation system, progressively moving through stages to reach the level of mastery. Accordingly, it is a good idea for educators not to give much pressure to the EFL learners to get things correct at the first time as learning needs process. They are also advisable to be alert to what goes on with the learners' learning process. They need to consider how the learners acquire negation by matching their instruction to the stage of the development. The fact that learners interpret information differently should also be used as guide line on how instruction of the information should be presented.

\section{REFERENCES}

[1] Ahmad (2002). Don’t just say “no”: developmental sequence of negation. Retrieved from https://www.american.edu/cas/t esol/pdf/upload/WP-2002-Ahmad-Developmental Sequence.pdf

[2] Butterworth, G. (1972). A Spanish-speaking adolescent's acquisition of English syntax. (Unpublished Master Thesis), University of California at Los Angeles, Los Angeles.

[3] Cancino, H., Rosansky, E. J., \& Schumann, J. H. (1978). The acquisition of English negatives and interrogatives by native Spanish speakers. In E. M. Hatch (Ed.), Second language acquisition: A book of readings (pp. 207-230). Rowley: Newbury House.

[4] Eisouh, Z. S. (2011). Negation errors in English by University of Jordan students. Reading Improvement, 48(3), 139-151.

[5] Ellis, R. (2006). Second language acquisition. Cambridge: Cambridge University Press.
[6] Felix, S. W. (1981). The effect of formal instruction on second language acquisition. Language Learning, 31(1), 87-112.

[7] Fuli, L. \& Shuang, S. (2015). A Survey of acquisition of transferred negation of English syntax with reference to senior high school tefl in mainland China. English Language Teaching, 8(2), 55-69.

[8] Khany, R., \& Bazyar, A. (2014). Generative analysis of the acquisition of negation by Iranian EFL learners: A typological study. Journal of Research in Applied Linguistics Studies, 4(1), 62-87.

[9] James, C. (2013) Errors in language learning and use: Exploring error analysis (Applied linguistics and language study series). London: Routledge

[10] Klima, E. S., \& Bellugi, U. (1966). Syntactic regularities in the speech of children. In J. Lyons \& R. J. Wales (Eds.), Psycholinquistic papers: The proceedings of the 1966 Edinburgh conference (pp. 183-219). Edinburgh: Edinburgh University Press.

[11] Lightbrown \& Spada (2006). How languages are learned (revised edition). New York: Oxford University Press

[12] Maliheh, Y. and Daniel, M. (2014). Performance of negative sentences with regard to learners proficiency levels. International Journal of Multidisciplinary and Current Research. 2(5), 549-554

[13] Perales, S.; Mayo, M. P. G.; Liceras, J. M. (2009). The acquisition of L3 English negation by bilingual (Spanish/Basque) learners in an institutional setting. The International Journal of Bilingualism, 13(1), 3-33

[14] Saville-Troike, M. (2012). Introducing second language acquisition. Cambridge: Cambridge University Press.

[15] Stauble, A.M. (1984). A comparison of Spanish-English and a Japanese-English second language continuum: Negation and verb morphology. In R. Andersen (Ed.), Second languages: A cross-linguistic perspective (pp. 323-353). Rowley, MA: Newbury House.

[16] Wode, H. (1978). Developmental sequences in naturalistic L2 acquisition. In E. M. Hatch (Ed.), Second language acquisition (pp. 101-117). Rowley: Newbury House. 